\title{
Quantum of Choice: How learners' feedback monitoring decisions, goals and self-regulated learning skills are related
}

\author{
Ioana Jivet \\ TU Delft, Netherlands, Open \\ Universiteit, Netherlands \\ i.jivet@tudelft.nl \\ Manuel Valle Torre
TU Delft, Netherlands
m.valletorre@tudelft.nl
}

\author{
Jacqueline Wong \\ Erasmus University Rotterdam, \\ Netherlands \\ wong@essb.eur.nl \\ Marcus Specht \\ TU Delft, Netherlands \\ m.m.specht@tudelft.nl
}

\author{
Maren Scheffel \\ Ruhr-Universität Bochum, Germany \\ maren.scheffel@rub.de
}

\author{
Hendrik Drachsler \\ Goethe University Frankfurt and \\ DIPF, Germany \\ Open Universiteit, Netherlands \\ drachsler@dipf.de
}

\begin{abstract}
Learning analytics dashboards (LADs) are designed as feedback tools for learners, but until recently, learners rarely have had a say in how LADs are designed and what information they receive through LADs. To overcome this shortcoming, we have developed a customisable LAD for Coursera MOOCs on which learners can set goals and choose indicators to monitor. Following a mixedmethods approach, we analyse 401 learners' indicator selection behaviour in order to understand the decisions they make on the LAD and whether learner goals and self-regulated learning skills influence these decisions. We found that learners overwhelmingly chose indicators about completed activities. Goals are not associated with indicator selection behaviour, while help-seeking skills predict learners' choice of monitoring their engagement in discussions and time management skills predict learners' interest in procrastination indicators. The findings have implications for our understanding of learners' use of LADs and their design.
\end{abstract}

\section{CCS CONCEPTS}

- Applied computing $\rightarrow$ E-learning; • Human-centered computing $\rightarrow$ User centered design.

\section{KEYWORDS}

learning dashboard, customisable dashboard, learner goal, selfregulated learning, feedback

\section{ACM Reference Format:}

Ioana Jivet, Jacqueline Wong, Maren Scheffel, Manuel Valle Torre, Marcus Specht, and Hendrik Drachsler. 2021. Quantum of Choice: How learners' feedback monitoring decisions, goals and self-regulated learning skills are related. In LAK21: 11th International Learning Analytics and Knowledge Conference (LAK21), April 12-16, 2021, Irvine, CA, USA. ACM, New York, NY, USA, 12 pages. https://doi.org/10.1145/3448139.3448179

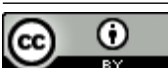

This work is licensed under a Creative Commons Attribution International 4.0 License

LAK21, April 12-16, 2021, Irvine, CA, USA

(C) 2021 Copyright held by the owner/author(s).

ACM ISBN 978-1-4503-8935-8/21/04 ..\$15.00

https://doi.org/10.1145/3448139.3448179

\section{INTRODUCTION}

Learning analytics dashboards (LADs) are feedback interventions designed to increase learner awareness, reflection and ability to self-regulate [27, 40]. However, unless dashboards are built for the purpose of facilitating a dialogue between students and teachers or academic advisers [18], LADs are passive displays of information and learners are seldom empowered to actively take part in the feedback process.

The 'one-size-fits-all' design has been questioned as research on student factors has shown to affect the impact of feedback interventions $[16,40]$. If we are to maximise the impact of LA and provide support for all learners without putting certain learners at a disadvantage, we first need to understand on which dimensions such interventions can and should be adapted. Therefore, instead of asking Are dashboards effective?, we argue that a more insightful question to ask is For whom are dashboards effective, why and under what circumstances?

Designing impactful student-facing LADs poses two challenges: selecting meaningful data for learners and visualising it in an intuitive way [14]. So far, the decision of what information is to be included in dashboards was driven by teachers, academics and institutions [42]. In this study, we address the first challenge with a learner-centred approach by empowering learners to make their own decision about what information they wish to see on a LAD. We have built a customisable dashboard on which learners can set goals and choose the information they wish to monitor as part of the process of (self-)regulating their learning towards achieving their goals. The LAD provides regularly updated feedback and has been embedded in two Coursera MOOCs. Based on the learners' interactions with the dashboards, we investigate the decisions learners took on the dashboard and the role of learner goals and self-regulated learning skills, two concepts closely connected to how learners process and use feedback [7], in these decisions.

\subsection{Feedback, goals and SRL}

Self-regulated learning (SRL) is a major research topic in educational psychology with numerous theoretical models that have been published and empirically verified [32]. Self-regulated learners make decisions not only about what, when and where to study, but they also set and adjust goals, choose fitting learning strategies, 
monitor their progress, evaluate the learning outcomes and the effectiveness of their learning strategies [45]. According to Zimmerman [44], the theoretical underpinning of this work, SRL is a social cognitive process achieved in cycles of (i) forethought, i.e., learning task analysis, goal setting and planning, (ii) performance, i.e. execution of the learning task and progress monitoring, and (iii) self-reflection, i.e., self-evaluation of outcomes.

Feedback is essential to how learners self-regulate [7]. Feedback is defined as information provided by various sources, human or computer, regarding outcomes and the cognitive processes that led to those outcomes $[7,17]$ and the process through which learners make sense of this information and use it to improve their learning and strategies [8]. While feedback has been shown to have the strongest influence on learning and achievement [17], not all types of feedback are equally effective. Hattie and Timperley distinguished between task-level, process-level, self-regulation-level and self-level feedback [17]. Feedback about the self is the least effective, while feedback about the process and self-regulation support deep processing and mastery of tasks. Task-level feedback is only useful when it adds to process- and self-regulation-level feedback. Moreover, a conceptual matrix of feedback [5] extending Hattie and Timperley's feedback model suggests that the complexity of the feedback should be adjusted to fit the learner's proficiency. Novice learners require task-level feedback, while process and selfregulatory feedback has more value to proficient learners.

To be effective, feedback also needs to address the gap between a learner's current and desired performance [30]. In the context of SRL, where learners are seen as active participants in their own learning [33], the desired state is defined by the goals that learners set for themselves. Literature differentiates between learning goals and performance goals $[15,36]$. Learning goals typically consist of a learning component to demonstrate acquisition of knowledge or skills or a change in behaviour and focus learners' attention on processes and strategies to acquire them. On the other hand, performance goals consist of a component related to completing the task on hand, without focusing on the role of strategies in completing tasks [36]. Feedback that helps learners understand the link between their performance and the cognitive activities they engage in while learning should be particularly effective for students who adopt learning goals [7]. The reason for that is that students who "emphasise learning goals over performance goals study more strategically" [33]. A third goal component that is of interest are time frames. Goals that have a specified time limit can be classified into proximal and distal goals [24]. By adding a time frame to a goal, learners create 'check-in point' for monitoring progress and self-regulating [28].

\subsection{Feedback with LADs}

In this work, we will investigate the connection between feedback, learner goal characteristics and self-regulated learning in the context of learning analytics dashboards, feedback tools designed to increase learner awareness, reflection and ability to self-regulate $[27,40]$. Such devices act as tools of agency, empowering learners to take informed decisions about their own learning [20]. The effectiveness of the feedback delivered with LADs is determined, in part, by the information that is presented to the learner, i.e., the indicators shown on the dashboard [14]. We will touch upon three shortcomings of existing LAD designs in terms of the information they display.

Firstly, although learning analytics emerged as the 'middle space' where learning and analytics meet [39], the analytics part has received more attention so far. Tools were created because of an abundance of learning data that became available and could be leveraged [26]. This issue is reflected in the type of data shown on dashboards. A literature review surveying 93 student-facing LA systems found that resource use is the most common information displayed on dashboards, present in $70 \%$ of surveyed systems [4], while time spent online was used in $30 \%$ of cases. LADs are still rarely informed by learning theory and do not provide learners with feedback on effective learning tactics and strategies [27]. Learners need both task-related feedback that improves learning outcomes, as well as process-related feedback that informs the needs for behavioural change, in order to self-regulate with dashboards [38].

Secondly, students are rarely consulted in deciding what information should be displayed on student-facing LADs [41]. West et al. [42] deem it unethical to assume that "we know what students want, what their concerns are or how they would like data presented". Learners need to be engaged in the decision making if such systems are to be accepted and adopted. Dollinger and Lodge [13] share a similar point of view and suggest that LA experts should look 'beyond themselves' and their expertise in order to innovate LA interventions. With the rise of human-centred learning analytics (HCLA) [6], more and more authors seek to engage critical stakeholders, identify their needs and design tools that address those needs. Through questionnaires, learners were asked what indicators are relevant for them in an academic advising dashboard [18] or what content should be included in an online self-assessment test for prospective students in online higher education [12]. Drawing from the $\mathrm{HCI}$ and information visualisation fields, Chatti et al. [9] proposed a human-centred indicator design (HCID) framework for LA to "get the right indicator" and to "get the indicator right" by actively involving learners in needs analysis, ideation, prototyping, and testing. In multiple studies, students expressed interest towards customisable dashboards that could fit their individual needs [2, 34]. Students want to be able to decide what information is displayed, how it is arranged and whether they are compared with peers. Next to engaging students in co-designing dashboards, making such displays customisable by the student can support student agency even further [2,31]. To our knowledge, there are no LA dashboards that offer learners the possibility to choose the displayed data.

Thirdly, the one-size-fits-all approach has long been criticised $[16,40]$, yet works that investigate the effects of goals and SRL on learners' needs, acceptance, and use of LA dashboards are rare. Regarding goals, although Beheshita et al. [1] provide empirical evidence that the effect of LA visualisations on students' behaviour can vary based on learners' goal orientations, existing LAD solutions mainly display indicators that support performance orientation $[20,38]$. One notable implementation that considers learners' goals is a MOOC interface that allows learners to select a learning objective from a set of predefined goals and offers tailored feedback [35]. Finally, although most LAD designers cite SRL theory as a theoretical background guiding the design [20,27], only a few studies investigated the way learners' SRL skills affect learner's perception 
and use of LADs. For example, as higher education students' SRL skills increase, so does the relevance they assign to different LAD design elements, e.g., transparency of design, reference frames and support for action [21].

\subsection{This study and RQs}

This study investigates learners' feedback needs from a LA dashboard and the effect of learner goals and SRL skills on these needs. To this end, we have designed and implemented a student-facing LAD with a twofold purpose. First, the dashboard was built as a real-time configurable feedback tool embedded in a MOOC platform. The tool supports learners' SRL processes following Zimmerman's SRL model [44] and offers a selection of both task-related and process-related indicators in line with Hattie and Timperley's feedback model [17] (see Section 2.1).

Secondly, the tool aids us, the researchers, in gaining insight into learners' metacognitive and self-regulating processes by observing the decisions they take about their learning. Data traces made by students when using configurable dashboards are a potentially rich source of information for this purpose [7, 22]. By enabling learners to practice their SRL skills, the interaction tracking component logs when learner load the widget, set or change goals, select or change indicators and submit the survey answers. Analysing the interaction data thus collected through the dashboard, we aim to answer the following research questions:

RQ1 What indicators do learners first choose to monitor on the dashboard?

RQ2 Is there a relationship between the way learners formulate their goals and the indicators they choose to monitor?

RQ3 Do the way learners formulate their goals and their SRL skills influence the choice of monitored indicators?

\section{THE LEARNING DASHBOARD}

\subsection{Design}

The dashboard provides support for each SRL phase as defined by Zimmerman [44]: (i) enables goal setting, by offering learners a space to formulate and record their goal; (ii) facilitates monitoring, by allowing learners to select indicators they wish to follow on a feedback widget; and (iii) prompts self-evaluation, by keeping both the goal and the feedback widget visible on the dashboard at all times. As we wish to observe learner behaviour and avoid introducing any bias in how learners set goals and select indicators, we do not provide learners with any information or support on SRL. The dashboard is shown in Figure 1.

At the top section of the dashboard, learners can set a goal and make changes to it later on (Figure 1(a) A). Learners are prompted with a question "What do you want to achieve by the end of this course?" and are suggested a few examples. Once the learner has saved a goal, upon return to the dashboard, they will see the goal displayed in this section (Figure 1(b) C).

Learners can choose to monitor between 3 to 6 indicators among 12 available options (Figure 1(a) B). The number of indicators learners can select is limited in order to compel them to prioritise. A minimum threshold nudges learners to monitor multiple indicators, giving learners a better picture of their learning and more information for us as to what learners deem valuable. The indicator list is randomized. To ensure a transparent design [21], indicator explanations are shown on-demand in a tooltip when learners hover on top of the indicator name. The 'Save' button becomes active only after learners selected at least 3 indicators. Once saved, a spider chart showing the values of the selected indicators is displayed (Figure 1(b) D). Further details about an indicator are displayed on demand when hovering over an axis of the spider chart. The control buttons on the right side of the widget allow learners to edit goals and monitored indicators and to look up further explanations on the selected indicators or FAQs related to the dashboard and this study (Figure 1(b) E). In line with the courses' weekly module structure, learners can change their indicator selection every week.

The dashboard offers two types of indicators defined to be in line with Hattie and Timperley's feedback framework [17]: six learning behaviour indicators, i.e., learning process level feedback, and six content progress indicators, i.e., task level feedback. In the conception of the indicators, we balanced the meaningfulness of indicators and the technical possibilities offered by the Coursera trace logs. We next describe the twelve indicators and the motivation behind including each one, starting with the learning behaviour indicators. The Content revision indicator reports the percentage of already completed learning activities that learners are revisiting. Revisiting assessments was associated with goal achievement and could suggest learners engage in retrieval practice [23]. Engagement in discussions, a measure of how active learners are on the forum by answering discussion prompts, posting questions, and replying to open threads, has been associated with higher achievement [10]. Productivity indicates the average percentage of activities that learners completed on the same day that they started them. The Online presence measures the amount of time learners spent so far on the pages of the course. Although time spent in a learning environment is not a useful predictor for achievement [25], it is very popular indicator among dashboard designers [4]. We wish to check to what extent is it interesting for learners. The last two learning behaviour indicators, Timing of starting activities and Timing of completing activities are proxies for learners' procrastination, a negative predictor for achievement [43]. They report how early in the week (in days), on average, learners start working on the weekly learning activities and how close to the end of the learning week, on average, they complete the learning activities. Similar indicators have been used in MOOCs dashboards [11]. The six content progress indicators report on the percentage of overall course activities as well as specific course activities learners completed and the course grade accumulated so far.

\subsection{Implementation}

The implementation consists of three parts: (a) data processing, (b) back end and (c) front end. Data processing computes the indicators displayed on the widget from the Coursera research data exports which contain over 100 tables with information such as course content, students' demographic data, students' interaction with each piece of course content, and forum data. Coursera processes research exports only at the end of each day and they become ready for download only after a delay. The data processing starts with a daily automated request of the previous day's data export. Once downloaded, the data export is processed with Python to calculate 
My learning dashboard

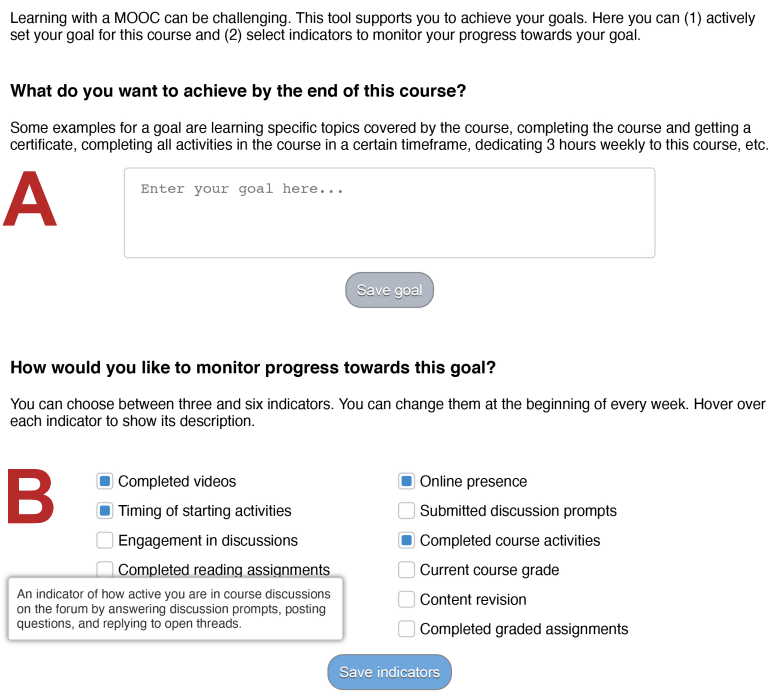

(a) Configuration view of the widget
My learning dashboard

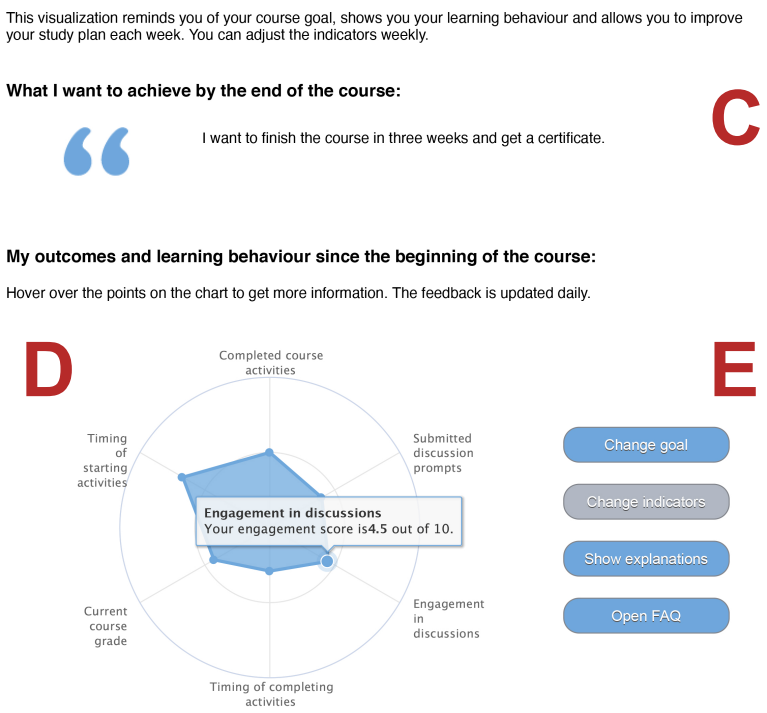

(b) The widget after configuration

Figure 1: The configurable learning dashboard: a) the configuration page that greets learners and b) a configured widget.

each learner's indicators which are stored in a MongoDB instance. Because of these added delays, the indicator values shown on the widget are two days old. In addition, the flags to allow students to edit their goals or indicator selection are reset every Sunday evening. The Coursera data processing code is available on Github ${ }^{1}$. The back end consists primarily of a Node.js server and has two purposes. Firstly, it handles the requests from the front end whenever a student loads the widget, and returns the corresponding dashboard configuration from the database, i.e., the goal, the indicator values and other flags. Secondly, it logs learners' interactions with the dashboard. Finally, the front end is the dashboard itself as shown in Figure 1, implemented as a Coursera plugin using HTML and Javascript. Being embedded as an ungraded learning activity in the course, learners do not need to leave the platform in order to interact with it. The code is available on Github ${ }^{2}$.

\section{METHODOLOGY}

\subsection{Context and study participants}

The dashboard was integrated in two Coursera MOOCs developed and run by Erasmus University of Rotterdam: a professional development course for higher education teachers on assessment (AHE) and a sustainability course on the role of businesses in achieving the Sustainable Development Goals (SDG). Both courses are in English and self-paced with flexible deadlines. The AHE course is an intermediate level course and estimates 18 hours to complete, while the SDG course is a beginner level course and estimates 15 hours.

\footnotetext{
${ }^{1}$ https://github.com/mvallet91/coursera-tracker-processing

${ }^{2}$ https://github.com/ioanajivet/DIY-LT
}

The two courses follow a similar learning design. The learning activities are organised into weeks and include video lectures, reading assignments, discussion prompts. The type of graded assignments that contribute to the final grade and determine whether learners pass the course differed: AHE requires learners to complete three peer-graded assignments and pass a final quiz exam, while SDG learners have to complete ten quizzes with both multiple choice and open-ended questions.

Based on the self-reported demographic data, learners in AHE are generally older $39.1 \pm 10.4$ years old, compared to $32.0 \pm 11.4$ in SDG. $54.4 \%$ of the AHE learners are female, while in SDG, $63.3 \%$ are female. AHE learners are highly educated, $29.6 \%$ have a $\mathrm{PhD}$ degree compared to only $3.3 \%$ in SDG, $45.6 \%$ have a masters degree compared to $38.5 \%$ in SDG and $21.9 \%$ of learners have only a bachelors degree in AHE compared to $50.0 \%$ in SDG. The two courses attract learners with different interests. Most learners in AHE are higher education teachers or are preparing themselves to become one. SDG learners are: students, business developers, entrepreneurs, marketing or sustainability consultants.

\subsection{Data collection and preparation}

The dashboard was added to the two MOOCs at different times and ran for 19 weeks in AHE and 14 weeks in SDG until October 2020. To facilitate access and integrate in the learning process, the dashboard was embedded within the first week of the course as an ungraded learning activity. Learners were reminded of its existence via the pre-programmed emails sent by the teaching team at the beginning of each week. Before gaining access to the dashboard, learners willing to participate were required to agree to a consent form embedded in the dashboard that detailed the purpose of the 
study, the data being collected and their rights. The study design and the consent form text were approved by the ethical research committee of the authors' institution. From the interaction data, we extracted the goals learners formulated, the indicators they selected, the answers to the SRL questionnaire and demographic data. In this paper, we analyse the initial dashboard configuration, i.e., first goal entered and the first selection of indicators made by learners.

Indicator selection data. The indicators selected by learners were coded as a set of 12 binary variables with a value of 1 for a selected indicator and 0 if the indicator was not selected. We extracted two additional variables from this data: the number of indicators selected (ordinal) and the percentage of learning behaviour indicators (continuous). We compute the percentage of learning behaviour indicators selected by learners in order to quantify the type of indicators selected while taking into account the number of selected indicators. For example, if learners selected four indicators on the widget and one indicator was a learning behaviour indicator, the value of this variable is $25 \%$. For each research question, we analyse the choices made by learners when selecting indicators through these three types of variables.

Goal formulation data. The goals learners formulated and recorded on the dashboard were saved as plain text. Following a qualitative analysis approach, we coded each goal into three binary variables describing the presence of a learning component, a performance component or a time frame in the text of the goal as motivated in section 1.1. Learning components were coded according to Bloom's taxonomy of educational learning objectives [3] to describe the complexity of the goals: (1) acquire knowledge on the topic, (2) understanding of the topic, (3) acquire skills related to the topic, (4) transfer the knowledge in their practice, (5) apply a learning strategy. Performance components were coded with references to (1) obtaining a certificate or (2) completing the course. As time frames, we coded both vague references to a point in time, e.g., "before September" or very specific references of deadlines, e.g., "in 2 weeks", because both of these suggest learners considered a time frame for achieving their goals.

SRL scores. As the setting of our study are MOOCs, we used a SRL questionnaire validated with MOOC learners [19]. The survey was embedded in the dashboard to increase the chances that learners fill it out. We collected 4 SRL subscale scores calculated as averages of the items within each scale: metacognitive activities before (7 items) and metacognitive activities after a learning task (6 items), time management (5 items) and help-seeking (6 items), 24 items in total rated on a 7-point Likert scale. The data collected showed high internal consistency on all 4 subscales as reflected by high values of the reliability Chronbach's $\alpha: .862, .821, .668, .880$ ( $\mathrm{N}=241$ - see Table 1), similar to the ones reported by the creators of the survey.

\subsection{Analyses}

To answer RQ1, we report and compare across the two courses the indicator selection data through Chi-square tests for the ordinal and binary variables and Mann-Whitney U test for the continuous variable. We also present frequent combinations of 2 and 3 indicators in each course. In answering RQ2, we present the coding results of the qualitative analysis of the goals formulated by learners and compare the outcomes between the two courses using the Chi-square tests. We then used an ordinal logistic regression for modelling the number of indicators selected by learners and 12 binomial logistic regressions, one for each indicator, predicting the probability of the indicator being selected, i.e., the reference level for the outcome variable is 0 . For modelling the percentage of learning indicators selected, we use a linear regression model as the predicted variable is continuous. The models include the course and three binary predictors, i.e., the presence of the three goal components described in section 4.2. For each model, we checked the multicollinearity statistics VIF values are within acceptable ranges. To answer RQ3, we present the descriptive statistics for the 4 SRL subscales scores and we extend all regression models from RQ2 by adding 4 continuous predictors, the 4 SRL skill scores. We conducted all analyses with jamovi (https://www.jamovi.org/).

Table 1: The number of learners included in each dataset used to answer the research questions.

\begin{tabular}{|c|c|c|c|c|}
\hline & \multirow[t]{2}{*}{ Total } & \multicolumn{2}{|c|}{ Course } & \multirow[t]{2}{*}{ Used for } \\
\hline & & AHE & SDG & \\
\hline Accessed the widget & 1711 & 845 & 866 & \\
\hline Accepted consent & 584 & 295 & 289 & \\
\hline Set indicators & 401 & 200 & 201 & RQ1 \\
\hline $\begin{array}{c}\text { Set indicators, goal and } \\
\text { SRL survey }\end{array}$ & 216 & 121 & 95 & RQ2, RQ3 \\
\hline
\end{tabular}

As we move from investigating RQ1 to RQ2 and RQ3, the number of participants included in each analysis depended on the extent to which the learners interacted with the dashboard (see Table 1). For RQ1, we include the data from all learners that set indicators, while for RQ2 and RQ3, we can only include the data from learners that set indicators, set a goal and answer the SRL questionnaire.

\section{RESULTS}

\subsection{Indicator selection (RQ1)}

The frequencies of the number of indicators selected by learners differ significantly between the two courses $\left(\chi^{2}(3, N=401)=\right.$ $21.0, p<.001)$. The maximum number of indicators, six, was selected by half of the learners in AHE, but only a third in the SDG (see Table 2). Another third of the SDG learners chose only three indicators on the widget, the minimum number of indicators required to configure the widget.

Learners in AHE $(M=39.7 \%, S D=20.0 \%$, Med $=33.3 \%)$ select significantly more learning behaviour indicators than learners in

Table 2: The number (\#L) and percentage (\%L) of learners that selected $3,4,5$ or 6 indicators in each course.

\begin{tabular}{|c|c|c|c|c|c|c|}
\hline & \multicolumn{2}{|c|}{ Total $(\mathrm{N}=401)$} & \multicolumn{2}{|c|}{$\operatorname{AHE}(\mathrm{N}=200)$} & \multicolumn{2}{|c|}{$\operatorname{SDG}(\mathrm{N}=201)$} \\
\hline & $\# \mathrm{~L}$ & $\% \mathrm{~L}$ & $\# \mathrm{~L}$ & $\% \mathrm{~L}$ & $\# \mathrm{~L}$ & $\% \mathrm{~L}$ \\
\hline 3 indicators & 101 & $25.2 \%$ & 39 & $19.5 \%$ & 62 & $30.8 \%$ \\
\hline 4 indicators & 54 & $13.5 \%$ & 22 & $11.0 \%$ & 32 & $15.9 \%$ \\
\hline 5 indicators & 69 & $17.2 \%$ & 28 & $14.0 \%$ & 41 & $20.4 \%$ \\
\hline 6 indicators & 177 & $44.1 \%$ & 111 & $55.5 \%$ & 66 & $32.8 \%$ \\
\hline
\end{tabular}


Table 3: Most commonly selected indicators showing the number and the proportion of learners within each course that selected each indicator. Most popular five indicators in each course are highlighted.

\begin{tabular}{|c|c|c|c|c|c|c|c|c|c|}
\hline & & \multicolumn{2}{|c|}{ Total $(\mathrm{N}=401)$} & \multicolumn{2}{|c|}{ AHE $(\mathrm{N}=200)$} & \multicolumn{2}{|c|}{ SDG $(\mathrm{N}=201)$} & \multicolumn{2}{|c|}{$\chi^{2}$} \\
\hline & & \# learners & $\%$ learners & \# learners & $\%$ learners & \# learners & $\%$ learners & Value & $\mathrm{p}$ \\
\hline \multicolumn{10}{|c|}{ Learning behaviour indicators } \\
\hline B1 & Content revision & 102 & $25.4 \%$ & 63 & $31.5 \%$ & 39 & $19.4 \%$ & 7.73 & $.005^{* *}$ \\
\hline B2 & Engagement in discussions & 122 & $30.4 \%$ & 74 & $37.0 \%$ & 48 & $23.9 \%$ & 8.15 & $.004^{* *}$ \\
\hline B3 & Productivity & 189 & $47.1 \%$ & 99 & $49.5 \%$ & 90 & $44.8 \%$ & 0.90 & .343 \\
\hline B4 & Online presence & 109 & $27.2 \%$ & 63 & $31.5 \%$ & 46 & $22.9 \%$ & 3.76 & .055 \\
\hline B5 & Timing of starting activities & 69 & $17.2 \%$ & 46 & $23.0 \%$ & 23 & $11.4 \%$ & 9.40 & $.002^{* *}$ \\
\hline B6 & Timing of completing activities & 117 & $29.2 \%$ & 62 & $31.0 \%$ & 55 & $27.4 \%$ & 0.64 & .423 \\
\hline \multicolumn{10}{|c|}{ Content progress indicators } \\
\hline $\mathrm{C} 7$ & Completed course activities & 251 & $62.6 \%$ & 114 & $57.0 \%$ & 137 & $68.2 \%$ & 5.33 & $.021^{*}$ \\
\hline $\mathrm{C} 8$ & Submitted discussion prompts & 95 & $23.7 \%$ & 59 & $29.5 \%$ & 36 & $17.9 \%$ & 7.45 & $.006^{* *}$ \\
\hline C9 & Completed graded assignments & 248 & $61.8 \%$ & 123 & $61.5 \%$ & 125 & $62.2 \%$ & 0.02 & .887 \\
\hline $\mathrm{C} 10$ & Completed reading assignments & 231 & $57.6 \%$ & 111 & $55.5 \%$ & 120 & $59.7 \%$ & 0.73 & .395 \\
\hline $\mathrm{C} 11$ & Completed videos & 241 & $60.1 \%$ & 122 & $61.0 \%$ & 119 & $59.2 \%$ & 0.14 & .713 \\
\hline $\mathrm{C} 12$ & Current course grade & 152 & $37.9 \%$ & 75 & $37.5 \%$ & 77 & $38.3 \%$ & 0.03 & .867 \\
\hline
\end{tabular}

Note: ${ }^{* * *} p<.001 ;{ }^{* *} p<.01 ;{ }^{*} p<0.05$.

the SDG course $(M=31.9 \%, S D=22.8 \%$, Med $=33.3 \%)$ as shown by a Mann-Whitney $U$ test $(U=15595, p<.001)$.

The frequency with which indicator was selected is shown in Table 3. The most popular indicators are highlighted, four of which are content progress indicators. These indicators have been selected by more than half of the learners in both courses. The fifth most commonly selected indicator is B3: Productivity, a learning behaviour indicator showing the percentage of learning activities completed on the same day on which they were started. The least popular indicators in both courses are a learning behaviour indicator, B5: Timing of starting activities, and a content progress indicator, C8: Submitted discussion prompts. There are significant differences between the two courses with regards to the popularity of several indicators as shown by the Chi-square tests in Table 3 . Three learning behaviour indicators are significantly more common in AHE: B1: Content revision, B2: Engagement in discussions and B5: Timing of starting activities. We noticed significant differences also in the selection frequency of C7: Completed course activities, being more frequent in SDG, and C8: Submitted discussion prompts, being more frequent in AHE. One observation worth mentioning is the fact that B2: Engagement in discussions and C8: Submitted discussion prompts, the two indicators related to the discussion forums, are significantly more common in AHE.

The pixel graphs in Figure 2 visualise the most commonly chosen combinations of two and three indicators in each course. Each line in the pixel graph shows the chosen combination of indicators marked by blue squares. We also report the number and quota of learners who included each combination in their indicator selection. These visualisations illustrate the focus on the content progress indicators as most blue squares are located on the right side of each graph. The graphs also illustrate the scarcity of learning behaviour indicators in the widget configurations, exception being B3: Productivity in both courses. A notable difference between the two courses highlighted by these graphs is the presence of B2: Engagement in discussions among indicator selection of AHE learners, as also shown by the results shown in Table 3. The most common combination is the same in both courses: completed course activities and graded assignments, being selected by $39.0 \%$ of the learners in AHE and $44.8 \%$ in SDG. In both courses, the six most common pairs or triples of indicators are a combination of the following indicators: completed course activities, graded assignments, reading assignments and videos.

\subsection{Indicator selection and learner goals (RQ2)}

Goal typology. Table 4 lists the distribution of learning, performance and time components in the goals that learners formulated in the two courses. The majority of learners in both courses formulated goals that included a learning component, while only a third included a performance component in their written goal. Only a modest portion of learners mentioned a time frame in their written goal. In most cases, the time frame was mentioned together with a performance component, e.g., "complete the course within the next two months". A substantial number of learners formulated goals that included both a learning and a performance component (see bottom of Table 4). The Chi-square tests showed that there is significant association between the course learners participated in and the presence of a learning component. This relation is further explained when looking at the fine-details of the goal formulations. Learners enrolled in the AHE course mentioned more frequently the acquisition of skills in their goal formulation, while learners in the SDG courses were more interested in obtaining knowledge about the topic of the course, understanding concepts or relations between the concepts taught in the course and applying it in their practice. There are no associations between the course and the presence of a performance component or a time frame in the goals formulated by learners.

Indicator selection. The results of the ordinal logistic regression using the course and the presence of the three goal components as predictors are reported in Table 5 . Results show a satisfactory goodness of fit to our data $\left(\chi^{2}(4,216)=12.50, p=.014\right)$. However, when looking at the model coefficients in Table 6 , the single most significant predictor is the course in which learners are enrolled in. As the reference level for the course variable is AHE and the 


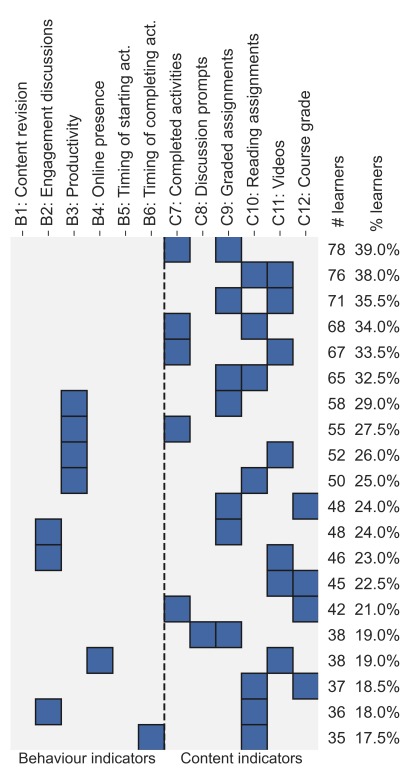

(a) 2 indicators in $\mathrm{AHE}$

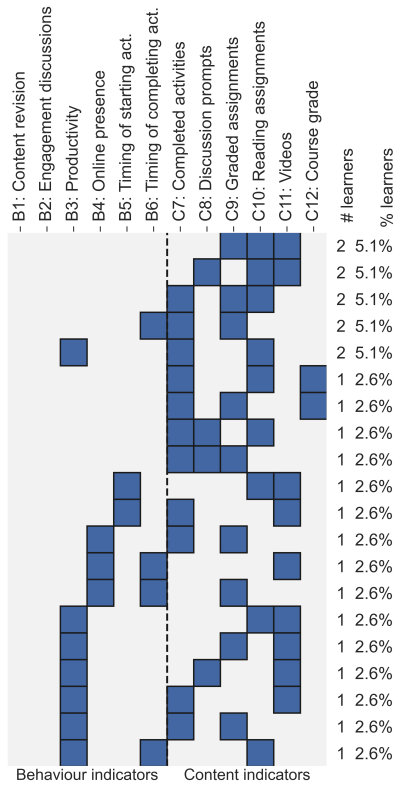

(b) 3 indicators in $\mathrm{AHE}$

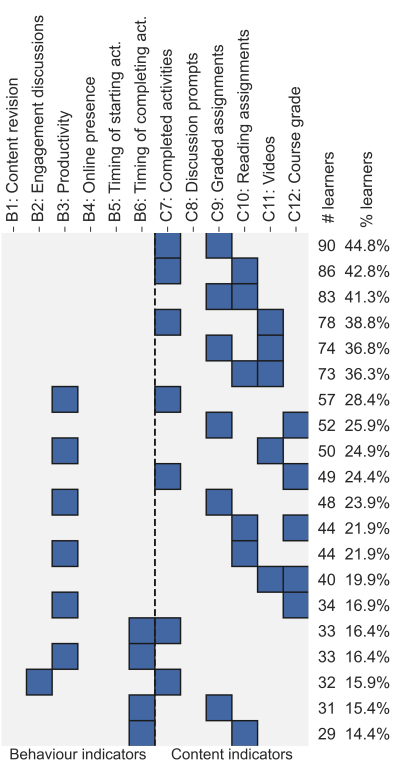

(c) 2 indicators in $\mathrm{AHE}$

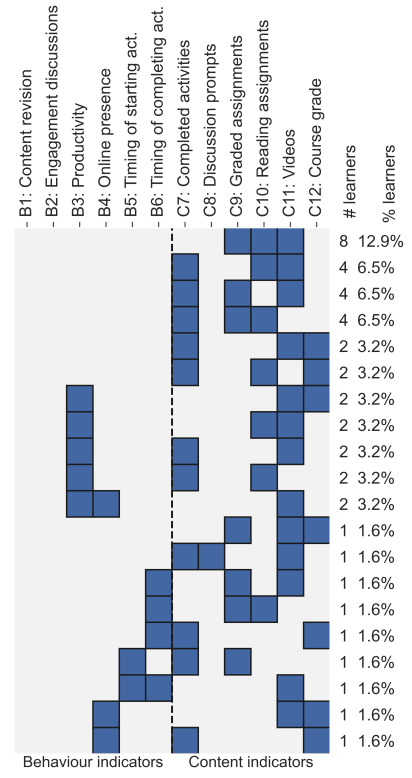

(d) 3 indicators in AHE

Figure 2: The twenty most frequent combinations of 2 and 3 indicators in the two courses, along with the number and percentage of learners that included these combinations in their indicator selection.

Table 4: The number and percentage of learners that used each type of goal component in their goals and Chi-square tests comparing these values across the two courses.

\begin{tabular}{|c|c|c|c|c|c|c|c|c|}
\hline & \multicolumn{2}{|c|}{ Total $(\mathrm{N}=215)$} & \multicolumn{2}{|c|}{ AHE $(\mathrm{N}=120)$} & \multicolumn{2}{|c|}{ SDG (N=95) } & \multicolumn{2}{|c|}{$\chi^{2}(\mathrm{df}=1)$} \\
\hline & \# learners & $\%$ learners & \# learners & $\%$ learners & \# learners & $\%$ learners & Value & $\mathrm{p}$ \\
\hline Learning component & 192 & $89.3 \%$ & 102 & $85.0 \%$ & 90 & $94.7 \%$ & 5.26 & $.022^{*}$ \\
\hline Knowledge & 88 & $40.9 \%$ & 38 & $31.7 \%$ & 50 & $52.6 \%$ & 9.64 & $.002^{* *}$ \\
\hline Understanding & 38 & $17.7 \%$ & 12 & $10.0 \%$ & 26 & $27.4 \%$ & 11.0 & $<.001^{* * *}$ \\
\hline Skills & 70 & $32.6 \%$ & 50 & $41.7 \%$ & 20 & $21.1 \%$ & 10.3 & $.001^{* *}$ \\
\hline Transfer & 81 & $37.7 \%$ & 38 & $31.7 \%$ & 43 & $45.3 \%$ & 4.17 & $.041^{*}$ \\
\hline Strategy & 14 & $6.5 \%$ & 8 & $6.7 \%$ & 6 & $6.3 \%$ & 0.01 & .918 \\
\hline Performance component & 72 & $33.5 \%$ & 43 & $35.8 \%$ & 29 & $30.5 \%$ & 0.39 & .413 \\
\hline Certificate & 50 & $23.3 \%$ & 32 & $26.7 \%$ & 18 & $18.9 \%$ & 1.77 & .183 \\
\hline Complete course & 54 & $25.1 \%$ & 31 & $25.8 \%$ & 23 & $24.2 \%$ & 0.07 & .785 \\
\hline Time frame & 21 & $9.8 \%$ & 10 & $8.3 \%$ & 11 & $11.6 \%$ & 0.634 & .426 \\
\hline Only learning comp. & 142 & $66.0 \%$ & 77 & $64.2 \%$ & 65 & $68.4 \%$ & & \\
\hline Only performance comp. & 23 & $10.7 \%$ & 18 & $15.0 \%$ & 5 & $5.3 \%$ & & \\
\hline Both types of comp. & 50 & $23.3 \%$ & 25 & $20.8 \%$ & 25 & $26.3 \%$ & & \\
\hline
\end{tabular}

Note: ${ }^{* * *} p<.001 ;{ }^{* *} p<.01 ;{ }^{*} p<0.05$.

estimate is negative and odds ratios below 1 , results indicate that learners in SDG are two times more likely to select a lower number of indicators $(O R=0.417,95 \% C I(0.245,0.704))$. The way learners formulated their goals does not explain this difference in behaviour. The linear regression model describing the percentage of learning behaviour indicators based on the same four predictors did not show satisfactory model fit $(F(4,210)=2.39, p=.052)$.

The results of the binomial logistic regressions predicting whether each indicator was selected or not show satisfactory models compared to the null model for three learning behaviour indicators (see
Table 5): B2: Engagement in discussions, B4: Online presence and B5: Timing of starting activities. In all three cases, the single significant predictor is the course in which learners are enrolled. The way learners formulate their goals was not found to be predictive of the indicators learners selected. We did not find any association between the predictor variables and the selection of content progress indicators, as none of these models show satisfactory goodness of fit (see right side Table 5). 
Table 5: Summary of logistic regression analyses using the course and three goal components as predictor variables to model the number of indicators selected (ordinal) and the selection of indicators (binomial).

\begin{tabular}{|c|c|c|c|c|c|c|c|c|c|c|c|c|c|c|}
\hline \multicolumn{7}{|c|}{ Learning behaviour indicators } & \multicolumn{8}{|c|}{ Content progress indicators } \\
\hline & \multirow[b]{2}{*}{ Deviance } & \multirow[b]{2}{*}{ AIC } & \multirow[b]{2}{*}{$\mathbf{R}^{2} \mathbf{M c F}$} & \multicolumn{3}{|c|}{ Overall model test } & & & \multirow[b]{2}{*}{ Deviance } & \multirow[b]{2}{*}{ AIC } & \multirow[b]{2}{*}{$\mathbf{R}^{2} \mathbf{M c F}$} & \multicolumn{3}{|c|}{ Overall model test } \\
\hline Response variables & & & & $\chi_{2}$ & df & $\mathbf{p}$ & \multicolumn{2}{|c|}{ Response variables } & & & & $\chi_{2}$ & df & $\mathbf{p}$ \\
\hline B1 Content revision & 235 & 245 & 0.020 & 4.71 & 4 & .318 & $\mathrm{C} 7$ & Completed course activities & 268 & 278 & 0.011 & 3.05 & 4 & .549 \\
\hline B2 Engagement in discussions & 260 & 270 & 0.560 & 15.40 & 4 & $.004^{*}$ & $\mathrm{C} 8$ & Submitted discussion prompts & 243 & 253 & 0.029 & 7.36 & 4 & .118 \\
\hline B3 Productivity & 296 & 306 & 0.003 & 0.94 & 4 & .919 & $\mathrm{C} 9$ & Completed graded assignments & 282 & 292 & 0.012 & 3.43 & 4 & .489 \\
\hline B4 Online presence & 246 & 256 & 0.419 & 10.70 & 4 & $.030^{*}$ & C10 & Completed reading assignments & 293 & 303 & 0.009 & 2.63 & 4 & .621 \\
\hline B5 Timing of starting activities & 196 & 206 & 0.050 & 10.30 & 4 & $.036^{*}$ & $\mathrm{C} 11$ & Completed videos & 286 & 296 & 0.008 & 2.33 & 4 & .676 \\
\hline B6 Timing of completing activities & 257 & 267 & 0.029 & 7.70 & 4 & .103 & $\mathrm{C} 12$ & Current course grade & 285 & 295 & 0.014 & 3.92 & 4 & .417 \\
\hline Number of indicators selected & 511 & 525 & 0.024 & 12.50 & 4 & $.014^{*}$ & & & & & & & & \\
\hline
\end{tabular}

Table 6: Model coefficients for the ordinal and the binomial logistic regressions modelling whether indicators are selected.

\begin{tabular}{|c|c|c|c|c|c|c|c|c|c|c|c|c|c|c|c|c|}
\hline \multirow[b]{2}{*}{ Predictor } & \multicolumn{4}{|c|}{$\begin{array}{c}\text { Number of } \\
\text { indicators selected }\end{array}$} & \multicolumn{4}{|c|}{$\begin{array}{l}\text { B2: Engagement } \\
\text { in discussions }\end{array}$} & \multicolumn{4}{|c|}{$\begin{array}{l}\text { B4: Online } \\
\text { presence }\end{array}$} & \multicolumn{4}{|c|}{$\begin{array}{c}\text { B5: Timing of } \\
\text { starting activities }\end{array}$} \\
\hline & B & $\mathbf{Z}$ & $\mathbf{p}$ & OR & B & $\mathbf{Z}$ & $\mathbf{p}$ & OR & B & $\mathbf{Z}$ & $\mathbf{p}$ & OR & B & $\mathbf{Z}$ & $\mathbf{p}$ & OR \\
\hline Intercept & & & & & 0.10 & 0.18 & .859 & 1.10 & -0.79 & -1.33 & .184 & 0.45 & -1.81 & -2.77 & .006 & 0.16 \\
\hline Course (ref. AHE) & -0.88 & -3.25 & $.001^{* *}$ & 0.42 & -0.94 & -2.98 & $.003^{* *}$ & 0.39 & -0.77 & -2.36 & $.018^{*}$ & 0.46 & -1.01 & -2.53 & $.011^{*}$ & 0.37 \\
\hline \multicolumn{17}{|l|}{ Goal components } \\
\hline Learning & 0.16 & 0.34 & .735 & 1.17 & -0.32 & -0.61 & .545 & 0.72 & 0.28 & 0.48 & .629 & 1.32 & 0.59 & 0.95 & .340 & 1.81 \\
\hline Performance & 0.09 & 0.27 & .785 & 0.11 & -0.01 & -0.03 & .979 & 0.99 & 0.06 & 0.16 & .871 & 1.06 & 0.14 & 0.29 & .769 & 1.14 \\
\hline Time frame & 0.61 & 1.11 & .265 & 1.83 & -1.30 & -1.84 & .066 & 0.27 & -1.34 & -1.65 & .099 & 0.26 & 1.12 & 1.81 & .071 & 3.05 \\
\hline
\end{tabular}

Note: ${ }^{* * *} p<.001 ;{ }^{* *} p<.01 ;{ }^{*} p<0.05$.

\subsection{Indicator selection, learner goals and SRL skills (RQ3)}

To answer RQ3, we extend the regressions used in RQ2 by adding the four SRL skill scores measured as continuous variables as predictors. For context, the results of the SRL questionnaire are shown in Table 7. In both courses, learners self-report high metacognitive skills and lower time management and help seeking skills, although learners in AHE have significantly higher metacognitive skills than learners in SDG as shown by Mann-Whitney U tests.

Number of indicators selected. As shown in Table 8, adding the four SRL skills as predictors significantly improves the model (model comparison: $\left.\chi_{2}(4, N=216)=14.90, p=.005\right)$. Nonetheless, none of the four SRL skills shows a significant contribution to modelling the response variable (see Table 9. This indicates that the four SRL predictors jointly explain changes in the variance of the predicted variable, but there is not enough statistical power to sufficiently disentangle their effects. The course remains the only significant predictor, learners in SDG being twice as likely to choose a lower number of indicators than learners in $\operatorname{AHE}(O R=0.435,95 \% C I(0.249,0.756))$.

Percentage of learning behaviour indicators. By adding the four SRL skills as predictors to the linear regression model in RQ2, we did not obtain a significantly better goodness of fit (model comparison: $F(4,206)=0.767, p=.548)$ and the model remains unsatisfactory: $F(8,206)=2.39, p=.134$. Thus, based on our data, we cannot explain the percentage of learning behaviour indicators by referring to the goals learners formulated or their self-reported SRL skills.
Table 7: Descriptive statistics for each SRL subscale and Mann-Whitney $U$ test results comparing the two courses.

\begin{tabular}{|c|c|c|c|c|c|c|c|}
\hline & \multicolumn{3}{|c|}{$\operatorname{AHE}(\mathrm{N}=141)$} & \multicolumn{3}{|c|}{$\operatorname{SDG}(N=100)$} & \multirow{2}{*}{$\frac{\text { MW }}{\text { p }}$} \\
\hline & Mean & Med. & Std. & Mean & Med. & Std. & \\
\hline Metacogn. before & 5.33 & 5.43 & 1.22 & 4.85 & 5.00 & 1.03 & $<.001^{* * *}$ \\
\hline Metacogn. after & 5.74 & 6.00 & 1.00 & 5.51 & 5.50 & 0.94 & $.030^{*}$ \\
\hline Time management & 4.73 & 4.80 & 1.11 & 4.96 & 5.00 & 0.95 & .179 \\
\hline Help seeking & 3.87 & 4.00 & 1.54 & 3.74 & 3.83 & 1.36 & .575 \\
\hline
\end{tabular}

Note: ${ }^{* * *} p<.001 ;{ }^{* *} p<.01 ;{ }^{*} p<0.05$.

Indicator selection. After adding the four SRL skills as predictor variables, we found statistically significant associations between all eight predicting variables and the selection of three learning behaviour indicators (see Table 8). We discuss each model in turn. Regarding B2: Engagement in discussions, by taking into account SRL skills, we obtain a significantly better fitting model than only considering the course and learner goals (model comparison: $\left.\chi_{2}(4)=23.9, p<.001\right)$. The model coefficients listed in Table 9 show that the course remains a significant predictor for choosing this indicator. SDG learners are three times less likely to select this indicator than AHE learners $(O R=0.33,95 \% C I(0.17,0.67))$. Next to the course, help-seeking skills are a significant predictor for choosing to monitor this indicator $(p<.001)$. More specifically, the odds ratio indicate an increase of $71 \%(O R=1.71,95 \% C I(1.32,2.23))$ for the selection of this indicator with every unit increase of helpseeking skills. 
Table 8: Summary of logistic regression analyses using the course, goal components and SRL skills as predictor variables to model the number of indicators selected (ordinal) and the selection of indicators (binomial).

\begin{tabular}{|c|c|c|c|c|c|c|c|c|c|c|}
\hline & & \multirow[b]{2}{*}{ Deviance } & \multirow[b]{2}{*}{ AIC } & \multirow[b]{2}{*}{$\mathbf{R}^{2} \mathbf{M c F}$} & \multicolumn{3}{|c|}{ Overall model test } & \multicolumn{3}{|c|}{ Comparison to $\mathrm{RQ} 2$ model } \\
\hline & & & & & $\chi_{2}$ & df & $\mathbf{p}$ & $\chi_{2}$ & df & $\mathbf{p}$ \\
\hline \multicolumn{11}{|c|}{ Learning behaviour indicators } \\
\hline B1 & Content revision & 228 & 246 & 0.050 & 11.98 & 8 & .152 & 7.27 & 4 & .122 \\
\hline $\mathrm{B} 2$ & Engagement in discussions & 236 & 254 & 0.143 & 39.30 & 8 & $<.001^{* * *}$ & 23.9 & 4 & $<.001^{* * *}$ \\
\hline B3 & Productivity & 290 & 308 & 0.024 & 7.17 & 8 & .519 & 6.23 & 4 & .183 \\
\hline B4 & Online presence & 240 & 258 & 0.064 & 16.50 & 8 & $.036^{*}$ & 5.79 & 4 & .216 \\
\hline B5 & Timing of starting activities & 195 & 213 & 0.058 & 11.90 & 8 & .155 & 1.65 & 4 & .799 \\
\hline B6 & Timing of completing activities & 243 & 261 & 0.084 & 22.15 & 8 & $.005^{* *}$ & 14.4 & 4 & $.006^{* *}$ \\
\hline \multicolumn{11}{|c|}{ Content progress indicators } \\
\hline $\mathrm{C} 7$ & Completed course activities & 266 & 284 & 0.019 & 5.07 & 8 & .750 & 2.02 & 4 & .732 \\
\hline $\mathrm{C} 8$ & Submitted discussion prompts & 237 & 255 & 0.054 & 13.54 & 8 & .095 & 6.18 & 4 & .186 \\
\hline $\mathrm{C} 9$ & Completed graded assignments & 282 & 300 & 0.014 & 4.13 & 8 & .845 & 0.70 & 4 & .951 \\
\hline $\mathrm{C} 10$ & Completed reading assignments & 292 & 310 & 0.014 & 4.04 & 8 & .853 & 1.41 & 4 & .843 \\
\hline $\mathrm{C} 11$ & Completed videos & 279 & 297 & 0.032 & 9.13 & 8 & .331 & 6.81 & 4 & .147 \\
\hline $\mathrm{C} 12$ & Current course grade & 283 & 301 & 0.024 & 6.82 & 8 & .557 & 2.90 & 4 & .575 \\
\hline \multicolumn{2}{|c|}{ Number of indicators selected } & 496 & 518 & 0.052 & 27.30 & 8 & $<.001 * * *$ & 14.90 & 4 & $.005^{* *}$ \\
\hline
\end{tabular}

Modelling the selection of B4: Online presence using the data we collected remains a satisfactory fitting model even when including the SRL skills as additional predictors. However, the goodness of fit of the model has not improved over the model from RQ2 (model comparison: $\chi_{2}(4)=5.79 p=.216$ ). Learning goals and SRL skills do not predict whether learners select this indicator, the only significant predictor remains the course.

The third significant model predicts the selection of B6: Timing of completing activities. The SRL skill predictors significantly improve the model from RQ2 (model comparison: $\chi_{2}(4)=14.4, p=.006$ ). The selection of this indicator is predicted by the inclusion of a time frame in the learner goal. Namely, learners that add a time frame to their goal are three times more likely to select this indicator $(O R=3.68,95 \% C I(1.18,11.44))$. Furthermore, metacognitive skills used after learning and time management are both significant predictors. Every unit increase in metacognitive activities after learning decreases the probability of this indicator being selected by $53 \%$ $(O R=0.53,95 \% C I(0.31,0.90))$, while time management increase the probability by $68 \%(O R=1.68,95 \% C I(1.16,2.45))$.

Finally, worth noting is the fact that by considering SRL skills, we did not obtain a satisfactory model for B5: Timing of starting activities, in contrast to the one in RQ2. This indicates that the data we collected does not provide a good enough fit to this model in order to predict the selection of this indicator based on the way learners formulate goals and their SRL skills. We did not find any association between the predictor variables and the selection of content progress indicators of indicators, as none of these models show satisfactory goodness of fit (see Table 8).

\section{DISCUSSION}

Throughout this paper, we investigated the behaviour of learners when selecting indicators that they wish to monitor and analysed this behaviour in relation to goals learner formulated and their SRL skills. In answering RQ1, we found a surprising result regarding the number of indicators selected by learners. We expected most learners would choose to monitor six indicators, the maximum number possible, but in both courses, more than half of the learners chose less. Furthermore, a third of SDG learners chose only three indicators, the minimum. Further analyses in RQ2 and RQ3 showed that the number of indicators selected was not associated with the way learners formulate the goals or with the self-reported SRL skills. The only significant predictor was the course in which they participated. Namely, learners in AHE were twice more likely to select a higher number of indicators. Although learners had the opportunity to monitor up to six indicators, more than half of the learners settled with less than the maximum number of indicators possible. The percentage of learning behaviour indicators learners selected was not associated with learner goals or SRL skills in any of the analyses. Nonetheless, AHE learners choose significantly more learning behaviour indicators than SDG learners. These first results suggest learners in AHE chose to monitor more indicators and, among these indicators, a higher proportion were learning behaviour indicators. However, none of these behaviours could be explained by the way learners formulated their goals or SRL skills.

When examining the indicators selected by learners, our data showed similar patterns in both courses. Learners chose overwhelmingly content progress indicators, focusing in particular on indicators that report on completed learning activities and not the course grade. A notable exception is C8: Submitted discussion prompts, the least selected indicator out of the twelve possible options. This does not come as a surprise, considering that MOOC discussion forums are generally avoided by learners [10]. The most frequent learning behaviour indicator is B3: Productivity, showing the percentage of learning activities completed on the same day on which they were started. While this indicator describes the relation between starting and finishing an activity and might be encouraging learners to persevere and finish the learning activities they had started, it is still very closely connected to the idea of completing activities.

As analyses in RQ2 and RQ3 showed, the selection of content progress indicators could not be explained by learner goals and SRL skills. We have several hypotheses as to why learners focused on content progress indicators. Firstly, they are easier to understand 
Table 9: Predictors in the ordinal logistic regression (number of selected indicators) and the significant binomial logistic regressions (indicators) modelling whether indicators are selected.

\begin{tabular}{|c|c|c|c|c|c|c|c|c|c|c|c|c|c|c|c|c|}
\hline \multirow[b]{2}{*}{ Predictor } & \multicolumn{4}{|c|}{$\begin{array}{c}\text { Number of } \\
\text { indicators selected }\end{array}$} & \multicolumn{4}{|c|}{$\begin{array}{l}\text { B2: Engagement } \\
\text { in discussions }\end{array}$} & \multicolumn{4}{|c|}{$\begin{array}{l}\text { B4: Online } \\
\text { presence }\end{array}$} & \multicolumn{4}{|c|}{$\begin{array}{c}\text { B6: Timing of } \\
\text { completing activities }\end{array}$} \\
\hline & B & $\mathbf{Z}$ & $\mathbf{p}$ & OR & B & $\mathbf{Z}$ & $\mathbf{p}$ & OR & B & $\mathbf{Z}$ & $\mathbf{p}$ & OR & B & $\mathbf{Z}$ & $\mathbf{p}$ & OR \\
\hline Intercept & & & & & -2.77 & -2.17 & .030 & 0.06 & -1.47 & -1.19 & .236 & 0.23 & -1.79 & -1.46 & .145 & 0.17 \\
\hline Course (ref. AHE) & -0.83 & -2.94 & $.003^{* *}$ & 0.44 & -1.10 & -3.08 & $.002^{* *}$ & 0.33 & -0.71 & -2.03 & $.042^{*}$ & 0.49 & -0.34 & -1.01 & .312 & 0.71 \\
\hline \multicolumn{17}{|l|}{ Goal components } \\
\hline Learning & 0.12 & 0.24 & .809 & 1.13 & -0.40 & -0.68 & .496 & 0.67 & 0.34 & 0.57 & .570 & 1.40 & 0.11 & 0.20 & .839 & 1.12 \\
\hline Performance & 0.06 & 0.18 & .859 & 1.06 & 0.01 & 0.03 & .975 & 1.01 & 0.06 & 0.15 & .881 & 1.06 & -0.06 & -0.14 & .889 & 0.95 \\
\hline Time frame & 0.76 & 1.35 & .178 & 1.14 & -1.22 & -1.64 & .102 & 0.30 & -1.36 & -1.65 & .099 & 0.26 & 1.30 & 2.25 & $.025^{*}$ & 3.68 \\
\hline \multicolumn{17}{|l|}{ SRL skills } \\
\hline Meta before & 0.19 & 0.99 & .323 & 1.21 & -0.43 & -1.71 & .088 & 0.65 & 0.41 & 1.55 & .122 & 1.50 & 0.36 & 1.48 & .140 & 1.44 \\
\hline Meta after & 0.01 & 0.03 & .975 & 1.01 & 0.53 & 1.94 & .052 & 1.70 & -0.41 & -1.50 & .134 & 0.66 & -0.64 & -2.32 & $.020^{*}$ & 0.53 \\
\hline Time management & 0.19 & 1.28 & .201 & 1.21 & 0.02 & 0.10 & .919 & 1.02 & 0.13 & 0.74 & .459 & 1.14 & 0.52 & 2.73 & $.006^{* *}$ & 1.68 \\
\hline Help seeking & 0.17 & 1.67 & .095 & 1.19 & 0.54 & 4.04 & $<.001^{* * *}$ & 1.72 & 0.05 & 0.40 & .691 & 1.05 & 0.02 & 0.13 & .896 & 1.02 \\
\hline
\end{tabular}

and are immediately actionable. Although we tried to limit the amount of indicators we offer learners for selection to twelve, it is possible that being confronted with a multitude of choice, learners were overwhelmed and chose to stick with the familiar. This phenomenon is called the paradox of choice: the more options one has, the more difficult it is to make a choice [37]. Secondly, learners might have interpreted the indicators differently on the basis of their motivation. Previous research has shown that learners gather different insights from the same indicators [21]. For example, when asked to interpret a mock-up LAD, higher education students with a learning goal considered course grades a proxy for how much they have learned, while students with performance goals connected grades with the requirements for completing the course. In this study, learners with learning goals might view the number of activities completed as a proxy for how much knowledge they have covered, while for learners with performance goals completing activities brings them closer to finishing the course and obtaining the certificate. However, we cannot make any inferences with regards to their rationale as we did not collect any information about why and how learners decided which indicators to monitor.

Finally, another plausible explanation relates to feedback literacy (or lack thereof). Feedback literacy implies, among others, that learners recognise the value of feedback and understand that they have an active role in the feedback process [8]. Given that our content progress indicators can be seen as task-level feedback, the most ineffective type of feedback [17], the fact that learners avoided monitoring indicators like B1: Content revision and B5: Timing of starting activities are of concern. Nonetheless, with this knowledge at hand, we can now develop the dashboard interface further and evaluate various interventions that could support learners in recognising the value of learning behaviour feedback.

When modelling the learning behaviour indicators selection, two insights are of particular interest. Firstly, our results show that learners with higher help-seeking skills are significantly more likely to select and monitor B2: Engagement in discussions. Higher help-seeking skills allow learners to recognise their need of help and know where and when to look for it [45]. As MOOC discussion forums were designed as a space where learners can ask for help from teachers or peers [10], our results could suggest that forums are seen as sources of help only by those learners that are skilled in looking for help. Secondly, time management skills and including a time frame in their goal are significant predictors for the selection of B6: Timing of completing activities. All three concepts are related to prioritising and efficiently allocating time to learning tasks. As a proxy for procrastination, this indicator might provide learners with a cue for checking whether they are still on track and able to achieve their goals within the specified time frame.

Overall, our analyses showed that the course is the single most consistent variable that is a significant predictor for multiple indicators. We provide two possible explanations. Firstly, the populations of the two courses differ in terms of demographics and interests. Learners in AHE are mostly higher education teachers, older and highly educated compared to learners in SDG. We are considering expanding the analyses of this paper to include demographics analysis as future work. Secondly, the two courses have slightly different learning designs. The graded activities are peer-graded assignments in one course and weekly multi-choice quizzes in the other. While the learning design explains $69 \%$ of the variability in time learners spend in an online learning environment [29], it is possible that the learning design also affects the feedback needs of learners in a similar manner.

\subsection{Limitations}

The study has several limitations worth noting. Firstly, this study was set in a MOOC context with a heterogeneous learner population in terms of demographics and interests. Conducting a similar study with a homogeneous group, e.g., in higher education, could yield valuable practical insights, provided the data sources are rich enough to extract meaningful indicators. Secondly, the results of this study are dependent on the 12 indicators that we offered learners for selection. We aimed to provide meaningful learning behaviour indicators, but many alternatives had to be dismissed because the Coursera export data did not provide relevant data to compute such indicators. Future dashboard variations could allow an open text box where learners could provide their own suggestions. Lastly, we mention two methodological limitations. 
The coarse classification of goals into learning and performance components conceals numerous nuances that highlight different learner intentions as listed in Table 4. Using more detailed goal classifications, like the TASC model [28], could contribute to further understanding the relationship between learner goals and feedback needs. Finally, as with any study using self-reported data, we rely on learners' self-awareness and truthfulness.

\subsection{Implications and future research}

Despite the limitations, this study shows that making LADs customisable for learners and monitoring their interactions with such devices can provide insights on how students use LADs. in a natural setting. This approach allowed us to conduct a field study in which learners do not have to imagine how they would behave or reflect on past behaviour, a limitation of many small-scale studies. We publish the code open-source so it can be used for similar research.

Secondly, using a customisable dashboard, we collected information that sheds light on learners' metacognitive processes and self-regulated learning. We could observe the decisions they made with regards to what information they monitor in a learning environment. We cannot measure SRL in trace data unless we allow learners to practice it. Creating LA interventions that support SRL processes, e.g., goal setting fields, option to customise reference frames or displayed data, generates new types of learner data that could be used to investigate feedback literacy, goal setting skills, or the effect of learner agency on dashboard uptake or student performance. In the future, we will further investigate how indicator selection decisions relate to their goal achievement and the performance in the course.

Finally, a major challenge in this study was crafting the twelve indicators so that they are grounded in learning theory, easy to understand and could be computed using the Coursera trace data. Bringing the learning to analytics requires a systematic approach to (a) identify relevant concepts that supports learners in developing better learning strategies from learning sciences, and to (b) identify (or create) meaningful data sources to quantify these concepts.

\section{CONCLUSION}

This work investigated what data learners find meaningful on LADs and whether their goals and SRL skills affect this judgement. We did not find evidence that the way learners formulate their goals is related to the indicators that they monitored. SRL skills, namely help-seeking and time management, predict whether learners will choose to monitor engagement in discussions and a procrastination indicator, respectively. Thus, our results demonstrate that designing 'one-size-fits-all' dashboards puts certain learners at a disadvantage, as skilled learners are more inclined to monitor behaviours associated with higher achievement. Designing impactful LADs need to address learners' skills levels and also support novice learners in recognising the benefit of monitoring their learning behaviour and use of learning strategies. Findings of the current study give considerable impetus to work towards defining targeted feedback and its equivalence in the potential indicators that LA can provide.

\section{REFERENCES}

[1] S S Beheshitha, M Hatala, D Gašević, and S Joksimović. 2016. The role of achievement goal orientations when studying effect of learning analytics visualizations.
In Proc. of LAK'16. 54-63.

[2] L Bennett and S Folley. 2019. Four design principles for learner dashboards that support student agency and empowerment. Journal of Applied Research in Higher Education (2019).

[3] B S Bloom. 1956. Taxonomy of educational objectives: The classification of educational goals. New York: Longmans, Green. (1956).

[4] R Bodily and K Verbert. 2017. Review of research on student-facing learning analytics dashboards and educational recommender systems. IEEE Transactions on Learning Technologies 10, 4 (2017), 405-418.

[5] C Brooks, A Carroll, R M Gillies, and J Hattie. 2019. A matrix of feedback for learning. Australian fournal of Teacher Education 44, 4 (2019), 2

[6] S Buckingham Shum, R Ferguson, and R Martinez-Maldonado. 2019. Humancentred learning analytics. Journal of Learning Analytics (2019).

[7] D L Butler and P H Winne. 1995. Feedback and self-regulated learning: A theoretical synthesis. Review of educational research 65, 3 (1995), 245-281.

[8] D Carless and D Boud. 2018. The development of student feedback literacy: enabling uptake of feedback. Assessment \& Evaluation in Higher Education 43, 8 (2018), 1315-1325.

[9] M A Chatti, A Muslim, M Guesmi, F Richtscheid, D Nasimi, A Shahin, and R Damera. 2020. How to Design Effective Learning Analytics Indicators? A HumanCentered Design Approach. In EC-TEL'20. Springer, 303-317.

[10] L Corrin, P G De Barba, and A Bakharia. 2017. Using learning analytics to explore help-seeking learner profiles in MOOCs. In Proceedings. of LAK'17.

[11] D Davis, I Jivet, R F Kizilcec, G Chen, C Hauff, and G-J Houben. 2017. Follow the successful crowd: raising MOOC completion rates through social comparison at scale. In Proc. of LAK'17. 454-463.

[12] LEC Delnoij, JPW Janssen, KJH Dirkx, and RL Martens. 2020. Designing an Online Self-assessment for Informed Study Decisions: The User Perspective. In EC-TEL'20. Springer, 74-86.

[13] M Dollinger and J M Lodge. 2018. Co-creation strategies for learning analytics. In Proc. of LAK'18. 97-101.

[14] E Durall and B Gros. 2014. Learning Analytics as a Metacognitive Tool.. In CSEDU (1). $380-384$.

[15] C S Dweck. 1986. Motivational processes affecting learning. American psychologist 41, 10 (1986), 1040.

[16] D Gašević, S Dawson, T Rogers, and D Gasevic. 2016. Learning analytics should not promote one size fits all: The effects of instructional conditions in predicting academic success. The Internet and Higher Education 28 (2016), 68-84.

[17] J Hattie and H Timperley. 2007. The power of feedback. Review of educational research 77, 1 (2007), 81-112.

[18] I Hilliger, T De Laet, V Henríquez, J Guerra, M Ortiz-Rojas, M Á Zuñiga, J Baier, and M Pérez-Sanagustín. 2020. For Learners, with Learners: Identifying Indicators for an Academic Advising Dashboard for Students. In ECTEL20. Springer, 117130.

[19] R S Jansen, A Van Leeuwen, J Janssen, and L Kester. 2018. Validation of the revised self-regulated online learning questionnaire. In EC-TEL'18.

[20] I Jivet, M Scheffel, H Drachsler, and M Specht. 2017. Awareness is not enough: pitfalls of learning analytics dashboards in the educational practice. In EC-TEL'17. Springer, 82-96.

[21] I Jivet, M Scheffel, M Schmitz, S Robbers, M Specht, and H Drachsler. 2020. From students with love: An empirical study on learner goals, self-regulated learning and sense-making of learning analytics in higher education. The Internet and Higher Education 47 (2020), 100758.

[22] K Kitto, M Lupton, P Bruza, D Mallett, J Banks, S Dawson, D Gasevic, S Buckingham Shum, A Pardo, and G Siemens. 2020. Learning Analytics beyond the LMS: Enabling Connected Learning via Open Source Analytics in 'the wild'. (2020). https://ltr.edu.au/resources/ID14-3821_Kitto_Report_2020.pdf

[23] R F Kizilcec, M Pérez-Sanagustín, and J J Maldonado. 2017. Self-regulated learning strategies predict learner behavior and goal attainment in Massive Open Online Courses. Computers \& education 104 (2017), 18-33.

[24] E A Locke and G P Latham. 2002. Building a practically useful theory of goal setting and task motivation: A 35-year odyssey. American psychologist 57, 9 (2002), 705.

[25] L P Macfadyen and S Dawson. 2010. Mining LMS data to develop an "early warning system" for educators: A proof of concept. Computers \& education 54, 2 (2010), 588-599.

[26] Z Marzouk, M Rakovic, A Liaqat, J Vytasek, D Samadi, J Stewart-Alonso, I Ram, S Woloshen, P H Winne, and J C Nesbit. 2016. What if learning analytics were based on learning science? Australasian fournal of Educational Technology 32, 6 (2016).

[27] W Matcha, D Gasevic, A Pardo, et al. 2019. A systematic review of empirical studies on learning analytics dashboards: A self-regulated learning perspective. IEEE Transactions on Learning Technologies (2019).

[28] L McCardle, E A Webster, A Haffey, and A F Hadwin. 2017. Examining students' self-set goals for self-regulated learning: Goal properties and patterns. Studies in Higher Education 42, 11 (2017), 2153-2169. 
[29] O Nguyen, B Rienties, L Toetenel, R Ferguson, and D Whitelock. 2017. Examining the designs of computer-based assessment and its impact on student engagement, satisfaction, and pass rates. Computers in Human Behavior 76 (2017), 703-714.

[30] D J Nicol and D Macfarlane-Dick. 2006. Formative assessment and self-regulated learning: A model and seven principles of good feedback practice. Studies in higher education 31,2 (2006), 199-218.

[31] X Ochoa and AF Wise. 2020. Supporting the shift to digital with student-centered learning analytics. Educational Technology Research and Development (2020), 1-5.

[32] Ernesto Panadero. 2017. A review of self-regulated learning: Six models and four directions for research. Frontiers in psychology 8 (2017), 422.

[33] P R Pintrich and E V De Groot. 1990. Motivational and self-regulated learning components of classroom academic performance. Fournal of educational psychology 82, 1 (1990), 33.

[34] L D Roberts, J A Howell, and K Seaman. 2017. Give me a customizable dashboard: Personalized learning analytics dashboards in higher education. Technology, Knowledge and Learning 22, 3 (2017), 317-333.

[35] T Rohloff, D Sauer, and C Meinel. 2020. Students' Achievement of Personalized Learning Objectives in MOOCs. In L@S'20.147-156.

[36] D H Schunk. 2012. Learning theories an educational perspective (6th edition). Pearson.

[37] B Schwartz. 2004. The paradox of choice: Why more is less.

[38] G Sedrakyan, J Malmberg, K Verbert, S Järvelä, and P A Kirschner. 2020. Linking learning behavior analytics and learning science concepts: Designing a learning analytics dashboard for feedback to support learning regulation. Computers in Human Behavior 107 (2020)

[39] D Suthers and K Verbert. 2013. Learning analytics as a" middle space". In Proc. of LAK'13. 1-4.

[40] S D Teasley. 2017. Student facing dashboards: One size fits all? Technology, Knowledge and Learning 22, 3 (2017), 377-384.

[41] O Viberg, M Hatakka, O Bälter, and A Mavroudi. 2018. The current landscape of learning analytics in higher education. Computers in Human Behavior 89 (2018), 98-110.

[42] D West, A Luzeckyj, D Toohey, J Vanderlelie, and B Searle. 2020. Do academics and university administrators really know better? The ethics of positioning student perspectives in learning analytics. Australasian fournal of Educational Technology 36, 2 (2020), 60-70.

[43] J W You. 2015. Examining the effect of academic procrastination on achievement using LMS data in e-learning. Fournal of educational technology \& society 18, 3 (2015), 64-74.

[44] B J Zimmerman. 1990. Self-regulated learning and academic achievement: An overview. Educational psychologist 25, 1 (1990), 3-17.

[45] B J Zimmerman and M Martinez-Pons. 1990. Student differences in self-regulated learning: Relating grade, sex, and giftedness to self-efficacy and strategy use. fournal of educational Psychology 82, 1 (1990), 51. 